
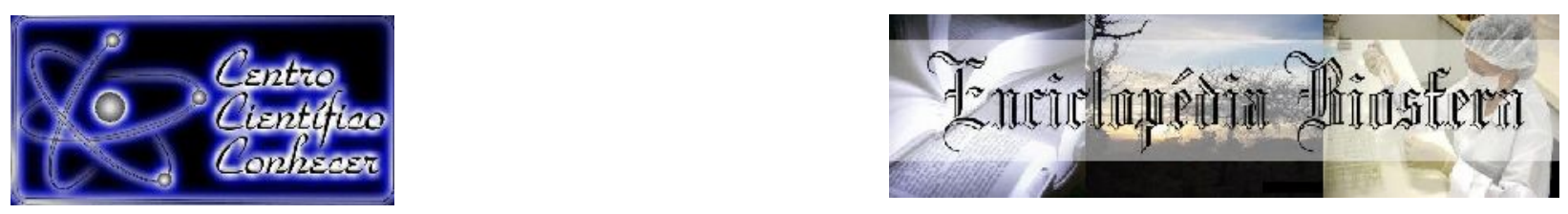

\title{
TREINAMENTO E DESENVOLVIMENTO DE PESSOAS NAS ORGANIZAÇÕES
}

\footnotetext{
Thaynara Braga Correia ${ }^{1}$, Emerson Gervásio de Almeida ${ }^{2}$

${ }^{1}$ Mestranda no Programa de Pós-Graduação em Gestão Organizacional da Universidade Federal de Catalão (UFCAT), Catalão, Goiás, Brasil (E-mail: thcorreia@ufcat.edu.br).

2 Docente Doutor no Programa de Pós-Graduação em Gestão Organizacional da Universidade Federal de Catalão (UFCAT), Catalão, Goiás, Brasil.

\section{Recebido em: 15/08/2021 - Aprovado em: 15/09/2021 - Publicado em: 30/09/2021 DOI: 10.18677/EnciBio 2021C43}

\begin{abstract}
RESUMO
A atuação do setor de Gestão de Pessoas e seu papel decisivo nas políticas de treinamento e desenvolvimento em organizações públicas ou privadas podem ser responsáveis pelo sucesso ou insucesso das estratégias organizacionais. Desta forma, capacitar os colaboradores para que melhor desempenhem suas funções em consonância com os objetivos do empregador surge como uma estratégia capaz de gerar benefícios para ambos. Entre os meses de outubro e novembro de 2020 foram utilizados os descritores "treinamento e desenvolvimento" para busca nos títulos de publicações indexadas em quatro bases de dados: Portal de Periódicos CAPES; Web of Science; Scopus e SciELO, com o objetivo de sistematizar estudos publicados entre 2015 e 2020 sobre treinamentos nas organizações e suas contribuições para as práticas de desenvolvimento dos recursos humanos. Dos 92 artigos encontrados, 11 atenderam aos critérios de inclusão. Houve destaque para trabalhos qualitativos que utilizaram questionários ou entrevistas na investigação. Em geral, os programas de T\&D avaliados trouxeram resultados positivos.
\end{abstract}

PALAVRAS-CHAVE: Estratégia Organizacional. Gestão de Pessoas. Treinamento e Desenvolvimento. 


\title{
PEOPLE'S TRAINING AND DEVELOPMENT IN ORGANIZATIONS: AN INTEGRATIVE REVIEW
}

\begin{abstract}
The performance of the People Management sector and its decisive role in training and development policies in public or private organizations may be responsible for the success or failure of organizational strategies. In this way, training employees to better perform their duties in line with the employer's objectives emerges as a strategy capable of generating benefits for both. Between the months of October and November 2020, the descriptors "training and development" were used to search the titles of publications indexed in 4 databases: Portal de Periódicos CAPES; Web of Science; Scopus and SciELO, with the objective of systematizing studies published between 2015 and 2020 on training in organizations and their contributions to human resource development practices. Among the 92 articles found, 11 met the inclusion criteria. Qualitative studies that used questionnaires or interviews in the investigation were highlighted. In general, the evaluated T\&D programs brought positive results.
\end{abstract}

KEYWORDS: Organizational Strategy. People management. Training and development.

\section{INTRODUÇÃO}

A Gestão de Pessoas (GP) tem conquistado espaço nos debates gerenciais, sendo amplamente considerada como área fundamental no atingimento dos objetivos estratégicos das organizações, sejam: públicas ou privadas, o que demanda um estrito alinhamento com a missão, visão, valores, cultura e estratégias organizacionais. Lidar com pessoas, de modo geral, não constitui tarefa simples e, considerando que empresas e instituições são essencialmente pensadas e compostas por seres humanos, detentores dos mais diversos perfis, cabe ao departamento de GP o mister de administrar este recurso tão valioso (TEIGA, 2012).

Para Ribeiro (2017), além da responsabilidade sobre etapas de recrutamento, seleção, treinamento, planos de cargos e salários, contratação, remuneração e questões trabalhistas, a área de gestão de pessoas também deve promover um ambiente de trabalho receptivo à diversidade de ideias, e ainda contribuir para o pleno desenvolvimento dos colaboradores.

O treinamento com o objetivo de desenvolver o trabalhador é utilizado como forma de adequar o indivíduo às suas respectivas funções, para que este as desempenhe da melhor maneira possível e em consonância com as metas empresariais (TREVELATO et al., 2018). Leite e Lott (2013) argumentam, no entanto, que a oferta pontual de programas de capacitação não se mostra interessante, tanto para o trabalhador como para a organização, em termos de evolução significativa para ambos.

Ao organizar um diagnóstico profundo das atuais competências dos colaboradores de um órgão ou empresa, o setor de gestão de pessoas estará apto a traçar planos de treinamento mais precisos que atendam às necessidades daquele empregador e ainda do próprio empregado (SILVA; CAMPOS, 2020), fornecendo mão-de-obra de qualidade ao primeiro e perspectivas de desenvolvimento pessoal e profissional ao segundo.

Os resultados de políticas bem estabelecidas de treinamento e desenvolvimento são reconhecidamente positivos (BAGATTOLI; MÜLLER, 2016; 
SILVA et al., 2017; SILVA; CAMPOS, 2020). A expectativa de crescimento que gira em torno deste processo motivacional que envolve 0 treinamento, 0 desenvolvimento e a possibilidade de ascensão na carreira, traduz-se no benefício da retenção de talentos. Ademais, Trevelato et al. (2018) afirmam ser mais econômico preparar adequadamente o público interno do que contratar pessoal com maiores qualificações.

Em um mundo globalizado, as empresas são submetidas a uma espécie de "seleção natural" para garantir a sobrevivência nos mercados, o que depende diretamente da capacidade de adaptação às exigências do ambiente em que se encontram inseridas. Os ajustes podem ocorrer em qualquer nível de atividade (seja na concepção de produtos e serviços, alterações na estratégia operacional, rotinas administrativas, capacidade tecnológica, desde o chão de fábrica até a alta administração), o que inclui o processo de desenvolver o capital humano da firma, para que esteja apto a auxiliá-la na obtenção de vantagens competitivas (SILVA; CAMPOS, 2020).

Silva e Miranda (2019) destacam ainda o papel dos gestores como agentes da mudança, no sentido de ser preciso também capacitá-los a gerenciar os processos de melhoria de desempenho dos funcionários, no intuito de minimizar possíveis resistências às alterações do status quo da organização, bem como reduzir sentimentos de estresse e insegurança envolvidos, situação que também se aplica ao setor público.

Dada a atualidade e relevância do tema no cenário de instituições públicas e privadas, nas quais as políticas de gestão de pessoas aplicadas podem ser responsáveis, por vezes, pelo sucesso ou insucesso da estratégia organizacional, justifica-se uma análise sobre os estudos contemporâneos relacionados ao treinamento e desenvolvimento de pessoas, com propósito de verificar o que está sendo produzido e como o tema vem sendo tratado pela agenda de pesquisa da área.

O presente trabalho, portanto, procura responder às seguintes questões: como os pesquisadores estão trabalhando a temática do treinamento e desenvolvimento de pessoas? Quais tipos de abordagens estão em evidência? O objetivo é estabelecer uma sistematização das análises mais recentes sobre treinamentos nas organizações e suas contribuições para as práticas de desenvolvimento dos recursos humanos.

\section{MATERIAL E MÉTODOS}

O método da Revisão Integrativa (RI) permite uma verificação holística sobre uma temática, possibilitando a inclusão de estudos experimentais e nãoexperimentais (SOUZA et al., 2010) para uma completa análise de conceitos, estratégias e teorias empregadas, abordagens, e ainda identificação de problemas metodológicos, que sejam comuns a um tópico de pesquisa escolhido (ERCOLE et al., 2014).

A RI, embora amplamente utilizada para a incorporação de evidências na saúde e na enfermagem (MENDES et al., 2008), tem a finalidade precípua de organizar de forma "sistemática, ordenada e abrangente" (ERCOLE et al., 2014, p. 9) os trabalhos científicos de um certo campo epistemológico, encontrando-se inserida na tipologia das revisões bibliográficas sistemáticas (BOTELHO et al., 2011), podendo ser direcionada para o objetivo de compilar resultados alcançados em pesquisas sobre determinado tema ou questão. 
Conforme mencionado na Introdução, as questões que nortearam o trabalho visaram identificar como os pesquisadores estão trabalhando a temática do treinamento e desenvolvimento de pessoas na atualidade e quais os tipos de abordagens que se encontram em evidência. Para responder a estas questões e atender ao objetivo proposto, foram utilizados os descritores "treinamento e desenvolvimento" para busca nos títulos de publicações indexadas em quatro bases de dados: Portal de Periódicos da Coordenação de Aperfeiçoamento de Pessoal de Nível Superior (CAPES/MEC); Web of Science; Scopus/Elsevier e Scientific Electronic Library Online (SciELO), na intenção de auferir maior variedade de artigos e também realizar o mesmo formato de pesquisa em todas as bases escolhidas.

A busca foi realizada entre os meses de outubro e novembro de 2020 e os seguintes critérios de inclusão foram estabelecidos: para ser selecionado, o artigo deveria ter sido publicado entre 2015 e 2020, com textos completos disponíveis para livre acesso, pertinentes ao tema "treinamento e desenvolvimento" relacionado à área de gestão de pessoas e/ou recursos humanos das organizações, sem distinção quanto ao idioma de publicação, descartando-se aqueles referentes a outras áreas do conhecimento, artigos repetidos, teses, dissertações e resumos submetidos a congressos. Para extração dos dados foi utilizada adaptação do protocolo validado por Ursi (2005).

Inicialmente, foram identificados 92 artigos cujos títulos mencionaram os descritores "treinamento e desenvolvimento", dos quais: 43 resultaram da consulta ao Portal de Periódicos CAPES; 17 da Web of Science; 12 da Scopus; e 20 da SciELO. Após leitura de todos os títulos e resumos, identificou-se que 47 não pertenciam ao escopo da área de conhecimento de interesse neste estudo, restando 45 trabalhos nesta fase de triagem. Deste total, 21 foram excluídos por serem duplicatas. Dentre os 24 artigos selecionados para verificação mais detalhada dos critérios de inclusão, 13 não atenderam aos requisitos de elegibilidade. Ao final, 11 artigos científicos demonstraram possuir os parâmetros necessários para a revisão em tela.

\section{RESULTADOS E DISCUSSÃO}

Para a apresentação dos resultados foram elaborados quadros sinópticos para melhor visualização das informações coletadas, adaptando-se ao caso o protocolo validado por Ursi (2005). O Quadro 1 traz aspectos gerais dos artigos selecionados, como o título, ano de publicação, autoria, instituição a que os autores são vinculados, base de dados em que o estudo foi encontrado, e o Nível de Evidência (NE) segundo classificação de Stetler et al. (1998). 
QUADRO 1- Dados gerais dos artigos incluídos na revisão integrativa.

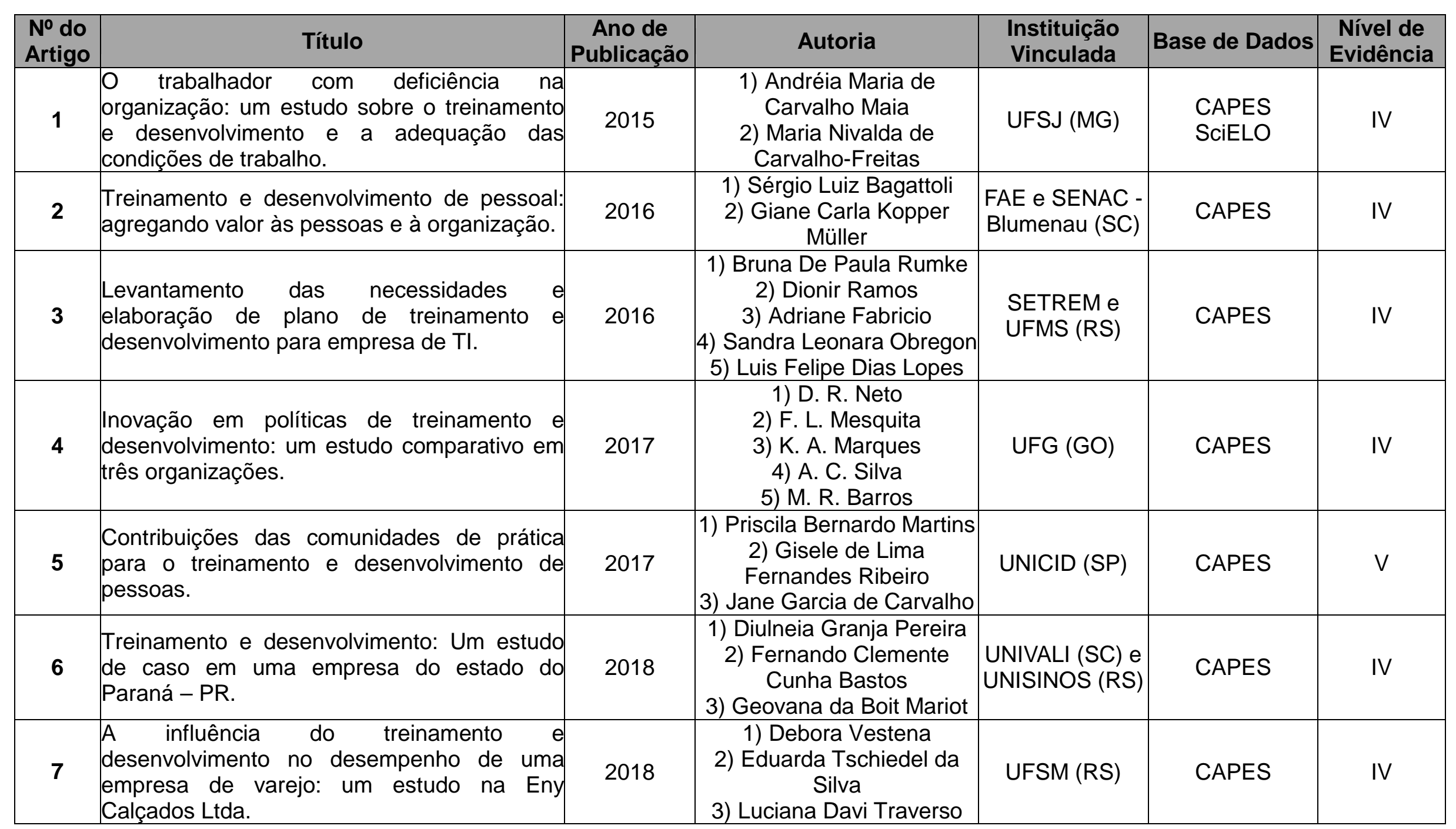




\begin{tabular}{|c|c|c|c|c|c|c|}
\hline & & & \begin{tabular}{|l|} 
4) Kamila Frizzo \\
5) Luana Inês Damke \\
6) Gabriela Rossato
\end{tabular} & & & \\
\hline 8 & $\begin{array}{l}\text { Ações de treinamento e desenvolvimento de } \\
\text { pessoal com foco na internacionalização: Um } \\
\text { estudo nas Universidades Públicas Federais } \\
\text { brasileiras. }\end{array}$ & 2018 & $\begin{array}{l}\text { 1) Francisca Waleska Bruno } \\
\text { Nunes } \\
\text { 2) Ivana Serra Rodrigues } \\
\text { Silva }\end{array}$ & UFC (CE) & $\begin{array}{c}\text { CAPES } \\
\text { SciELO } \\
\text { Web of Science }\end{array}$ & IV \\
\hline 9 & $\begin{array}{l}\text { Desenvolvimento e validação de um } \\
\text { programa de treinamento em liderança para } \\
\text { enfermeiros. }\end{array}$ & 2019 & \begin{tabular}{|c|} 
1) Beatriz Gonçalves \\
Martins \\
2) Lais Marques Coelho e \\
Silva \\
3) Beatriz Rodrigues Bispo \\
dos Santos Capaccioli \\
4) Vanessa Ribeiro Neves \\
5) Alexandre Pazetto \\
Balsanelli
\end{tabular} & UNIFESP (SP) & \begin{tabular}{|c|} 
CAPES \\
SciELO \\
Scopus \\
Web of Science
\end{tabular} & V \\
\hline 10 & $\begin{array}{l}\text { Análise da satisfação dos colaboradores em } \\
\text { relação a política de treinamento e } \\
\text { desenvolvimento em uma organização } \\
\text { multinacional de Cuiabá-MT. }\end{array}$ & 2019 & $\begin{array}{l}\text { 1) Rosicley Nicolao de } \\
\text { Siqueira } \\
\text { 2) Fabricio Cesar de } \\
\text { Moraes } \\
\text { 3) Andrey Sartory } \\
\text { 4) Ledian Cheila de Godoy } \\
\text { 5) Moises Phillip Botelho }\end{array}$ & $\begin{array}{l}\text { FATEC SENAI } \\
\text { (MT) }\end{array}$ & CAPES & IV \\
\hline 11 & $\begin{array}{l}\text { Ações de treinamento em uma universidade } \\
\text { pública, desenvolvimento profissional e } \\
\text { cidadania organizacional: existe relação entre } \\
\text { esses construtos? }\end{array}$ & 2020 & $\begin{array}{l}\text { 1) Maria Célia da Silva Lima } \\
\text { 2) Diva Ester Okazaki Rowe } \\
\text { 3) Luciana Mourão } \\
\text { 4) Abdinardo Moreira } \\
\text { Barreto Oliveira }\end{array}$ & \begin{tabular}{|} 
UNIVASF (PE), \\
UFBA (BA), \\
UNIVERSO \\
(RJ), UERJ (RJ) \\
e UTFPR (PR)
\end{tabular} & SciELO & IV \\
\hline
\end{tabular}

Fonte: Autores (2021). 
Os níveis de evidência de Stetler et al. (1998) utilizados no Quadro 1 são classificados em seis categorias: Nível I) indica pesquisa que utilizou de metanálise para sumarizar informações de estudos controlados; Nível II) estudo experimental individual; Nível III) estudo quase-experimental, realizado de forma controlada em um grupo de indivíduos, não randomizado, com pré e pós-teste, ou estudo do tipo "caso controle"; Nível IV) estudo não-experimental, como pesquisa descritiva correlacional, pesquisa qualitativa ou estudo de caso; Nível V) relatório de casos ou dados obtidos sistematicamente, de qualidade verificável, ou dados de programas de avaliação; e Nível VI) estudo baseado em opiniões de autoridades respeitadas, de autores conhecidos nacionalmente, de comitê de peritos ou de órgãos de regulamentação.

O Quadro 2, por sua vez, contempla os seguintes aspectos considerados pertinentes: objetivos dos artigos científicos, a abordagem adotada para resolução do problema, os procedimentos metodológicos escolhidos, as palavraschave/descritores utilizados na indexação e as principais conclusões dos autores. 
QUADRO 2 Objetivo, abordagem do problema, procedimentos metodológicos, descritores utilizados e principais conclusões.

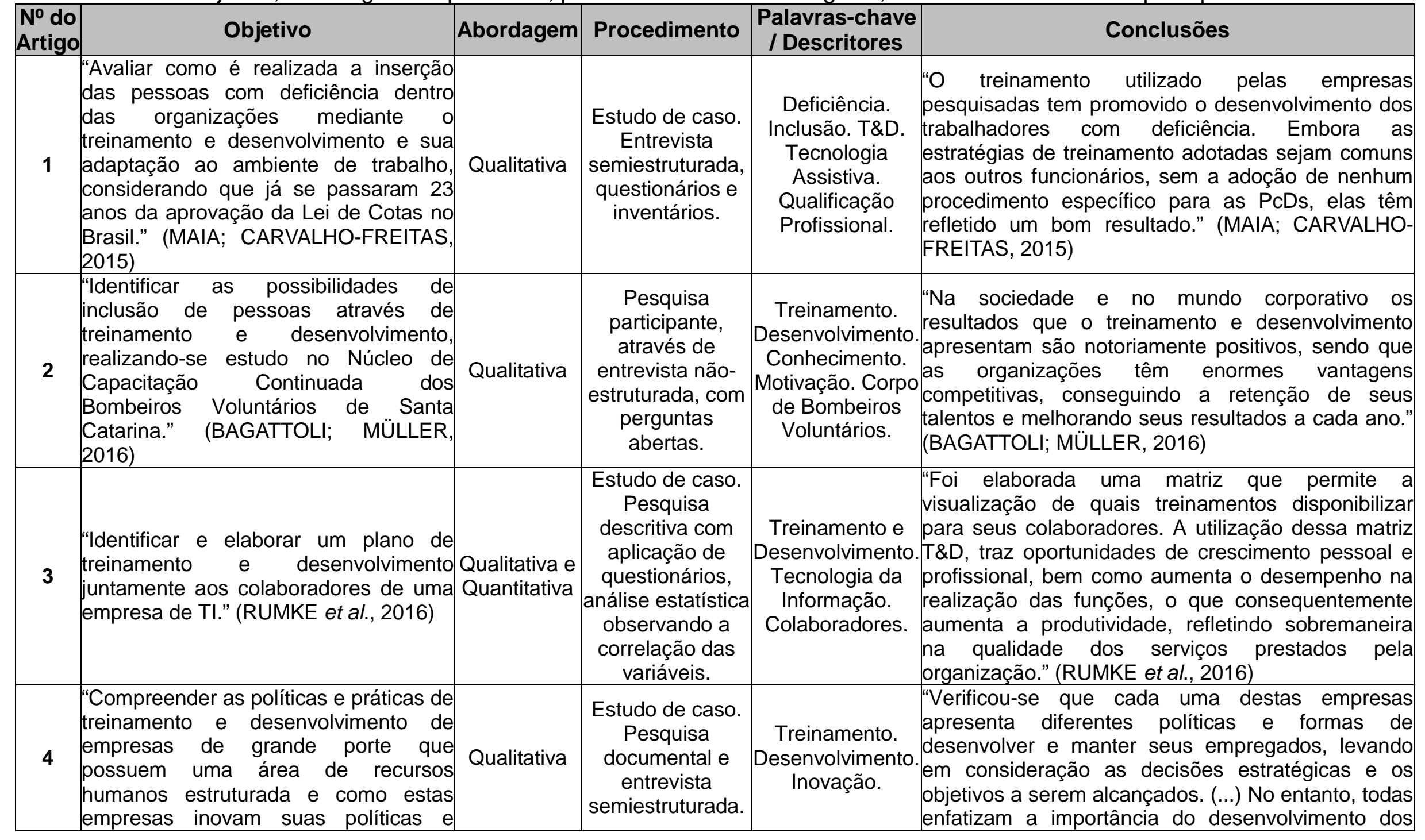

ENCICLOPÉDIA BIOSFERA, Centro Científico Conhecer - Jandaia-GO, v.18 n.37; p. 502 


\begin{tabular}{|c|c|c|c|c|}
\hline & \begin{tabular}{|l} 
práticas de desenvolvimento para \\
valorização dos colaboradores." \\
(RIBEIRO NETO et al., 2017)
\end{tabular} & & & $\begin{array}{l}\text { seus profissionais, levando em consideração a } \\
\text { velocidade nas mudanças de cenários vivenciados, } \\
\text { seja no mundo político, econômico e até mesmo } \\
\text { tecnológico." (RIBEIRO NETO et al., 2017) }\end{array}$ \\
\hline 5 & $\begin{array}{l}\text { "Apresentar características conceituais } \\
\text { de comunidades de prática e analisar } \\
\text { os benefícios entre as comunidades de } \\
\text { prática e o treinamento e e } \\
\text { desenvolvimento de pessoas." } \\
\text { (MARTINS et al., 2017) }\end{array}$ & Qualitativa & $\begin{array}{c}\text { Revisão } \\
\text { bibliográfica. }\end{array}$ & \begin{tabular}{|c|l|} 
Treinamento e & "As comunidades de prática podem estar inseridas \\
dentro das organizações, as quais, no entanto, terão \\
que adotar métodos e técnicas de ensino- \\
Desenvolvimento. aprendizagem compatíveis com os objetivos, \\
Comunidades & $\begin{array}{l}\text { conteúdos e objetos da capacitação. Como } \\
\text { Práticas. }\end{array}$ \\
Compequência, as comunidades de prática poderão \\
Essenciais. & $\begin{array}{l}\text { contribuir para o treinamento e desenvolvimento de } \\
\text { pessoas, pois oferecem aos integrantes acesso a } \\
\text { novo conhecimento para, assim, revelar valor } \\
\text { funcional." (MARTINS et al., 2017) }\end{array}$ \\
\end{tabular} \\
\hline 6 & $\begin{array}{l}\text { "Se propôs a analisar como ocorre o } \\
\text { processo de T\&D em uma empresa do } \\
\text { estado do Paraná." (PEREIRA et al., } \\
\text { 2018) }\end{array}$ & Qualitativa & $\begin{array}{l}\text { Estudo de caso. } \\
\text { Pesquisa } \\
\text { documental e } \\
\text { entrevista } \\
\text { semiestruturada. }\end{array}$ & \begin{tabular}{|c|l} 
& “É importante que o processo de levantamento de \\
necessidades não se concentre apenas nas \\
Treinamento. & necessidades identificadas pelos gestores, mas que \\
Desenvolvimento. & estas sejam compartilhadas por demais \\
Levantamento & interessados, principalmente o público direto da \\
das & $\begin{array}{l}\text { ação. Além disso, é importante que a área de RH } \\
\text { Necessidades de }\end{array}$ \\
amplie sua atuação, participando ativamente junto \\
Treinamento. & $\begin{array}{l}\text { aos gestores na identificação e estabelecimento de } \\
\text { ações de treinamento e desenvolvimento." } \\
\text { (PEREIRA et al., 2018) }\end{array}$
\end{tabular} \\
\hline 7 & $\left|\begin{array}{lrr}\text { “Identificar se } & \text { os } & \text { processos } \\
\text { Treinamento } & \text { e } & \text { Desenvolvimento } \\
\text { influenciam no } & \text { desempenhor da } \\
\text { empresa ENY." (VESTENA et al., 2018) }\end{array}\right|$ & Qualitativa & $\begin{array}{l}\text { Estudo de caso. } \\
\text { Entrevista } \\
\text { estruturada. }\end{array}$ & \begin{tabular}{c|l} 
& "A empresa procura sempre estar atualizada, \\
Treinamento e & considerando-se as rápidas transformações do \\
Desenvolvimento. mercado, sendo que os programas de Treinamento \\
Desempenho. & e Desenvolvimento realizados com os funcionários \\
Colaboradores. & $\begin{array}{l}\text { da empresa impactam positivamente o desempenho } \\
\text { da mesma." (VESTENA et al., 2018) }\end{array}$
\end{tabular} \\
\hline 8 & $\begin{array}{l}\text { "Pesquisar as ações desenvolvidas na } \\
\text { área de Recursos Humanos } \\
\text { direcionadas para o treinamento e } \\
\text { desenvolvimento de staff (docentes e } \\
\text { servidores técnicos-administrativos) }\end{array}$ & Qualitativa & $\begin{array}{l}\text { Pesquisa } \\
\text { descritiva com } \\
\text { aplicação de } \\
\text { questionário. }\end{array}$ & \begin{tabular}{|l|l} 
Internacionalizaç "Apesar de haver um interesse e investimento na \\
ão. Treinamento. \\
área de recursos humanos para desenvolvimento e \\
Desenvolvimento. \\
treinamento de staff universitário que vise à \\
Staff Acadêmico. \\
promoção da internacionalidade da educação \\
superior, as universidades ainda têm um importante
\end{tabular} \\
\hline
\end{tabular}




\begin{tabular}{|c|c|c|c|c|c|}
\hline & $\begin{array}{l}\text { Com foco no processo de } \\
\text { internacionalização nas Universidades } \\
\text { Públicas Federais no Brasil." (NUNES; } \\
\text { SILVA, 2018) }\end{array}$ & & & & $\begin{array}{l}\text { desafio no fomento de ações e estratégias que } \\
\text { englobem a internacionalização." (NUNES; SILVA, } \\
\text { 2018) }\end{array}$ \\
\hline 9 & $\begin{array}{l}\text { "Identificar as estratégias que facilitam } \\
0 \text { desenvolvimento da liderança, } \\
\text { correlacionando-as com variáveis de } \\
\text { caracterização, e construir e validar um } \\
\text { programa para treinamento em } \\
\text { liderança para enfermeiros." (MARTINS } \\
\text { et al., 2019) }\end{array}$ & Quantitativa & \begin{tabular}{|c|} 
Estudo \\
transversal + \\
estudo de \\
validação de \\
programa (técnica \\
Delphi). Utilizou- \\
se os testes de \\
Mann-Whitney e \\
Kruskal Wallis.
\end{tabular} & $\begin{array}{l}\text { Liderança. } \\
\text { Enfermagem. } \\
\text { Educação } \\
\text { Continuada. } \\
\text { Hospitais de } \\
\text { Ensino. Recursos } \\
\text { Humanos de } \\
\text { Enfermagem. }\end{array}$ & $\begin{array}{l}\text { "Construir um treinamento a partir das expectativas } \\
\text { dos participantes foi um diferencial desta pesquisa, } \\
\text { pois permitiu o conhecimento das reais } \\
\text { necessidades destes profissionais e o planejamento } \\
\text { s de um programa adequado a elas." (MARTINS et al., } \\
\text { 2019) }\end{array}$ \\
\hline 10 & $\begin{array}{llll}\text { “Avaliar o nível de } & \text { satisfação dos } \\
\text { colaboradores a } & \text { respeito dos } \\
\text { treinamentos e } & \text { desenvolvimento } \\
\text { proporcionados por } & \text { uma empresa } \\
\text { multinacional no } & \text { no ramo r de } \\
\text { concessionárias de caminhões e ônibus } \\
\text { (transportes) localizada em Cuiabá- } \\
\text { MT.” (SIQUEIRA et al., 2019) }\end{array}$ & $\begin{array}{l}\text { Qualitativa e } \\
\text { Quantitativa }\end{array}$ & \begin{tabular}{|c|} 
Pesquisa \\
descritiva com \\
aplicação de \\
questionário e \\
realização de \\
teste de \\
hipóteses pela \\
distribuição $T-$ \\
Student. \\
\end{tabular} & $\begin{array}{c}\text { Concessionária } \\
\text { de Caminhões e } \\
\text { Ônibus. } \\
\text { Treinamento. } \\
\text { Desenvolvimento. } \\
\text { Colaboradores. }\end{array}$ & $\begin{array}{l}\text { "A política de treinamento e desenvolvimento } \\
\text { humano na empresa proporciona satisfação para os } \\
\text { participantes. Ressalta-se que a empresa investindo } \\
\text { em seu capital intelectual, estará sempre preparada } \\
\text { para inovações, novas tecnologias e concorrências." } \\
\text { (SIQUEIRA et al., 2019) }\end{array}$ \\
\hline
\end{tabular}

Fonte: Autores (2021). 
Os 11 (onze) artigos selecionados estavam todos disponíveis em português, publicados, em sua maioria (27\%), no ano de 2018. O Portal de Periódicos CAPES/MEC foi à base de dados que retornou a maior parte dos trabalhos $(91 \%)$, enquanto que dois dos três (27\%) indexados na SciELO, e um dos dois $(18 \%)$ indexados na Web of Science também foram encontrados na base de Periódicos CAPES. Um (9\%) artigo foi identificado unicamente na base Scopus da Elsevier.

No quesito autoria, todos os trabalhos foram concebidos por dois ou mais autores, sendo as publicações por cinco autores a parcela mais relevante da amostra (36\%). Observou-se que um dos artigos foi produzido em conjunto por autores de diferentes regiões do País, entretanto, quanto aos demais, $40 \%$ concentraram-se em instituições da Região Sul, seguido pela Região Sudeste $(30 \%)$.

Um total aproximado de $82 \%$ dos artigos foi considerado possuidor de nível de evidência IV, segundo a classificação de Stetler et al. (1998). Dez trabalhos (91\%) utilizaram na metodologia instrumentos como questionário ou entrevista e $45 \%$ declararam expressamente tratar-se de estudo de caso. Apenas um pretendeu realizar revisão bibliográfica.

Neste sentido, $64 \%$ dos artigos adotaram abordagem qualitativa; 27\% priorizaram abordagem qualitativa e quantitativa; e $9 \%$ optaram pela abordagem exclusivamente quantitativa. Embora não haja padronização, em $91 \%$ foram escolhidas como palavras-chave/descritores os termos "treinamento" e "desenvolvimento", escritos juntos, separados ou ainda ligados a outro vocábulo.

É possível observar, a partir dos dados obtidos, relativa tendência dos estudos que envolvem treinamento e desenvolvimento de pessoas na escolha por instrumentos metodológicos como questionário ou entrevista e na realização de estudos preferencialmente não-experimentais, como pesquisa descritiva correlacional, pesquisa qualitativa ou estudo de caso. Seguindo essa ótica, as políticas de gestão de pessoas de instituições públicas e privadas podem avaliar suas necessidades e estratégias de acordo com as contribuições para as práticas de desenvolvimento dos recursos humanos aqui sistematizadas.

Verificou-se que entre 2015 e 2020 houve certa constância na quantidade de publicações relacionadas à área de Treinamento e Desenvolvimento (T\&D), o que pode ser explicado pela atualidade e relevância do tema no cenário das organizações, compondo discussões contínuas nos meios acadêmicos e organizacionais em razão da importância estratégica do capital humano.

Quanto às características básicas dos artigos, entende-se que a utilização de descritores em português pode ter influenciado no retorno de trabalhos exclusivamente na língua pátria. As publicações por cinco autores são comuns em eventos científicos, enquanto que as regiões Sul e Sudeste concentram instituições de pesquisa consolidadas com programas de graduação e pós-graduação reconhecidos nacionalmente. Um dos motivos do Portal de Periódicos CAPES ser a base de dados com maior percentual de retorno de artigos, pode envolver a vinculação deste a diversas bases de dados, incluindo Scopus, SciELO e Web of Science, que podem ser acessadas pelo próprio portal (CAPES, 2020).

Quanto às metodologias, a utilização de questionários e entrevistas e, essencialmente, da abordagem qualitativa para análise dos dados (MAIA; CARVALHO-FREITAS, 2015; BAGATTOLI; MÜLLER, 2016; RIBEIRO NETO et al., 2017; PEREIRA et al., 2018; VESTENA et al., 2018; NUNES; SILVA, 2018), traduz a necessidade dos pesquisadores estabelecerem certa proximidade com o público- 
alvo de sua investigação e de observarem todos os aspectos subjetivos entrelaçados ao escopo da pesquisa, de forma a refletir resultados confiáveis atrelados às políticas de treinamento e desenvolvimento.

Os objetivos propostos nos trabalhos analisados convergem no sentido de procurarem examinar os resultados e a eficácia de programas de treinamento (NUNES; SILVA, 2018; LIMA et al., 2020); avaliar políticas de desenvolvimento profissional (RIBEIRO NETO et al., 2017; PEREIRA et al., 2018); mensurar o nível de satisfação dos colaboradores com estes tipos de ações (SIQUEIRA et al., 2019; LIMA et al., 2020); verificar critérios pertinentes à inclusão de funcionários à corporação mediante o treinamento (MAIA; CARVALHO-FREITAS, 2015; BAGATTOLI; MÜLLER, 2016); validar propostas de programas (RUMKE et al., 2016; MARTINS et al., 2019); e ainda, apurar os reflexos destes no desempenho organizacional (MARTINS et al., 2017; VESTENA et al., 2018).

De maneira geral, os resultados e conclusões dos artigos da amostra apresentaram resultados positivos e benefícios concatenados às políticas de treinamento e desenvolvimento investigadas (BAGATTOLI; MÜLLER, 2016; RUMKE et al., 2016; VESTENA et al., 2018; LIMA et al., 2020).

\section{CONCLUSÃO}

A literatura fornece relatos promissores associados às boas práticas de treinamento e desenvolvimento nas organizações. O presente trabalho procurou sumarizar de forma sistemática as pesquisas realizadas entre 2015 e 2020 sobre a temática do treinamento e desenvolvimento e verificar como o assunto estava sendo abordado. O resultado da investigação veio ao encontro do que fora preconizado pela teoria básica apresentada e corroborou para uma compreensão holística do fenômeno.

O arcabouço acadêmico encontrado avaliou que os programas de capacitação devem ser concebidos para melhor se adaptar às limitações dos funcionários, considerando-se, por exemplo, questões de diversidade e acessibilidade. Para além desse entendimento, tão importante quanto as estratégias de treinamento traçadas pelos gestores é justamente agregar a opinião do público-alvo das ações, o que permitiria identificar as reais demandas de capacitação e adequá-las ao propósito institucional.

O método de pesquisa empregado permitiu elencar práticas contributivas à gestão do desenvolvimento de recursos humanos, com destaque para as vantagens de tornar possível aos colaboradores o crescimento pessoal e profissional, além das narrativas quanto aos ganhos de produtividade associados e melhorias na qualidade da prestação de serviços. Estudos apontaram que em mercados competitivos, que demandam rápida adaptabilidade por parte das organizações, há reconhecimento dos gestores quanto à importância de desenvolver seus profissionais e fortalecer o desempenho em relação aos concorrentes. Por outro lado, um artigo relatou dificuldades dos trabalhadores na aplicação do conteúdo aprendido à realidade das unidades de trabalho.

Dentre as limitações da pesquisa encontram-se o uso de descritores não controlados, em razão da falta de padronização que acomete algumas áreas das ciências sociais aplicadas. $O$ uso exclusivo de palavras-chave em português e a dificuldade de associações com outros descritores também comprometem a quantidade de artigos retornados pelas bases de dados. 
Os achados do presente estudo expressaram resultados positivos e benefícios relacionados às políticas de treinamento e desenvolvimento nas instituições, entretanto, um dos trabalhos ( $\left.n^{0} 11\right)$ chamou a atenção para possíveis obstáculos na aplicação e/ou compartilhamento do conhecimento adquirido em capacitações nas rotinas dos locais de trabalho. Sugere-se que pesquisas futuras ampliem o foco sobre esta perspectiva.

\section{REFERÊNCIAS}

BAGATTOLI, S. L.; MÜLLER, G. C. K.. Treinamento e desenvolvimento de pessoal: agregando valor às pessoas e à organização. Navus-Revista de Gestão e Tecnologia, v. 6, n. 2, p. 106-120, 2016. Disponível em: $<$ https://www.redalyc.org/pdf/3504/350454046009.pdf>.

BOTELHO, L. L. R.; CUNHA, C. C. de A.; MACEDO, M. O método da revisão integrativa nos estudos organizacionais. Gestão e sociedade, v. 5, n. 11, p. 121136, $2011 . \quad$ Disponível em: <https://www.gestaoesociedade.org/gestaoesociedade/article/view/1220>. DOI: https://doi.org/10.21171/ges.v5i11.1220.

CAPES, PORTAL PERIÓDICOS. Portal periódicos CAPES. Disponível em: https://www-periodicos-capes-gov-br.ezl.periodicos.capes.gov.br/index.php?, 2020.

ERCOLE, F. F.; MELO, L. S. de; ALCOFORADO, C. L. G. C. Revisão integrativa versus revisão sistemática. Revista Mineira de Enfermagem, v. 18, n. 1, p. 9-12, 2014. Disponível em: <http://www.reme.org.br/artigo/detalhes/904>. DOI: http://www.dx.doi.org/10.5935/1415-2762.20140001.

LEITE, P. A. R.; LOTT, T. C. C. Treinamento e desenvolvimento organizacional, uma ferramenta nas empresas atuais. Revista Científica Semana Acadêmica. Fortaleza, $\quad$ v. $42, \quad$ n. $1,42013.4$ Disponível em: <https://semanaacademica.com.br/system/files/artigos/treinamento_e_desenvolvime nto_organizacional_uma_ferramenta_nas_empresas_atuais.pdf $>$.

LIMA, M. C. D. S.; ROWE, D. E. O.; MOURÃO, L.; OLIVEIRA, A. M. B. Ações de treinamento em uma universidade pública, desenvolvimento profissional e cidadania organizacional: existe relação entre esses construtos? Organizações \& Sociedade, v. 27, n. 92, p. 152-170, 2020. Disponível em: <https://www.scielo.br/j/osoc/a/ydhRR4mZQX4fRTzDTx8Ms6h/?lang=pt\&stop=next\&f ormat=html>. DOI: https://doi.org/10.1590/1984-9270928.

MAIA, A. M.de C.; CARVALHO-FREITAS, M. N. de. O trabalhador com deficiência na organização: um estudo sobre o treinamento e desenvolvimento e a adequação das condições de trabalho. REAd. Revista Eletrônica de Administração (Porto Alegre), v. 21, n. 3, p. 689-718, 2015. Disponível em: <https://www.scielo.br/j/read/a/8FtgbLMD35r8TTFVYvnXWKr/?format=html\&lang=pt> . DOI: https://doi.org/10.1590/1413-2311.0722014.54834. 
MENDES, K. D. S.; SILVEIRA, R. C. de C. P.; GALVÃO, C. M. Revisão integrativa: método de pesquisa para a incorporação de evidências na saúde e na enfermagem. Texto \& contexto enfermagem, v. 17, n. 4, p. 758-764, 2008. Disponível em: <https://www.scielo.br/j/tce/a/XzFkq6tjWs4wHNqNjKJLkXQ/?lang=pt\&format=html>. DOI: https://doi.org/10.1590/S0104-07072008000400018.

MARTINS, B. G.; SILVA, L. M. C.; CAPACCIOLI, B. R. B. D. S.; NEVES, V. R.; BALSANELLI, A. P. Desenvolvimento e Validação de Um Programa de Treinamento em Liderança para Enfermeiros. Texto \& Contexto-Enfermagem, v. 28, 2019. Disponível em: <https://www.scielo.br/j/tce/a/MWnjTVxsY3SX5FRvczNLX5F/abstract/?lang=pt>. DOI: https://doi.org/10.1590/1980-265X-TCE-2018-0048.

MARTINS, P. B.; RIBEIRO, G. L. F.; CARVALHO, J. G. Contribuições das Comunidades de Prática para o Treinamento e Desenvolvimento de Pessoas. Research, Society and Development, v. 4, n. 4, p. 239-250, 2017. Disponível em: <https://www.rsdjournal.org/index.php/rsd/article/view/7>. DOI: https://doi.org/10.17648/rsd-v4i4.7.

NUNES, F. W. B.; SILVA, I. S. R. Ações de treinamento e desenvolvimento de pessoal com foco na internacionalização: um estudo nas universidades públicas federais brasileiras. Revista Gestão Universitária na América Latina-GUAL, v. 11, n. $4, \quad$ p. $82-99, \quad 2018 . \quad$ Disponível em: $<$ https://periodicos.ufsc.br/index.php/gual/article/download/1983-

4535.2018v11n4p82/37668>. DOI: https://doi.org/10.5007/1983-4535.2018v11n4p82.

PEREIRA, D. G.; BASTOS, F. C. C.; MARIOT, G. da B. Treinamento e desenvolvimento: um estudo de caso em uma empresa do estado do Paraná PR. Revista Vianna Sapiens, v. 9, n. 2, p. 27-27, 2018. Disponível em: <https://viannasapiens.emnuvens.com.br/revista/article/view/267>. DOI: https://doi.org/10.31994/rvs.v9i2.267.

RIBEIRO, A. de L. Gestão de pessoas. Saraiva Educação SA, 2017. E-book.

RIBEIRO NETO, D.; MESQUITA, F. L.; MARQUES, K. A.; SILVA, A. C.; BARROS, M. R. Inovação em políticas de treinamento e desenvolvimento: um estudo comparativo em três organizações. HOLOS, v. 5, p. 228-237, 2017. Disponível em: $<$ https://www.redalyc.org/pdf/4815/481554850019.pdf>. $10.15628 /$ holos.2017.4849

RUMKE, B. D. P.; RAMOS, D.; FABRICIO, A.; OBREGON, S. L.; LOPES, L. F. D. Levantamento das necessidades e elaboração de um plano de treinamento e desenvolvimento para uma empresa de Tl. Revista de Carreiras e Pessoas (ReCaPe)| ISSN-e: 2237-1427, v. 6, n. 2, 2016. Disponível em: <https://revistas.pucsp.br/ReCaPe/article/view/29357>

SILVA, J. D. da; CAMPOS, D. C. de. Treinamento e desenvolvimento de pessoas: a importância da gestão de pessoas. Gestão, Inovação e Empreendedorismo, v. 3, 
n. $1, \quad$ p. $19-29, \quad 2020 . \quad$ Disponível em: <http://ojs.faculdademetropolitana.edu.br/index.php/revista-gestaoinovacao/article/view/32>.

SILVA, L. F. da; MIRANDA, R. C. da R. Resistência a mudanças no serviço público: a visão da área de treinamento e desenvolvimento de pessoas. Cadernos da Escola do Legislativo-e-ISSN: 2595-4539, v. 18, n. 29, p. 179-210, 2019. Disponível em: $<$ https://cadernosdolegislativo.almg.gov.br/seer/index.php/cadernos-

ele/article/viewFile/114/86>.

SILVA, M. C.; GOMES JÚNIOR, W. V.; VALDATI, A. B.; WILLERDING, I. A. V.; LAPOLLI, É. M. Treinamento e desenvolvimento de pessoas e seu impacto no atingimento de metas de vendas na era do conhecimento. Revista da Universidade Vale do Rio Verde, v. 15, n. 2, p. 20-35, 2017. Disponível em: <http://periodicos.unincor.br/index.php/revistaunincor/article/view/3397>. DOI: http://dx.doi.org/10.5892/ruvrd.v15i2.3397

SIQUEIRA, R. N. de; MORAES, F. C. de; SARTORY, A.; GODOY, L. C. de; BOTELHO, M. P. Análise da satisfação dos colaboradores em relação a política de treinamento e desenvolvimento em uma organização multinacional de CuiabáMT. Revista Estudos e Pesquisas em Administração, v. 3, n. 2, p. 82-95, 2019. Disponível

em: <https://periodicoscientificos.ufmt.br/ojs/index.php/repad/article/view/8572>. DOI: 10.30781/repad.v3i2.8572.

SOUZA, M. T. de; SILVA, M. D. da; CARVALHO, R. de. Revisão integrativa: o que é e como fazer. Einstein (São Paulo), v. 8, n. 1, p. 102-106, 2010. Disponível em: <https://www.scielo.br/j/eins/a/ZQTBkVJZqcWrTT34cXLjtBx/abstract/?lang=pt>. DOI: https://doi.org/10.1590/S1679-45082010RW1134.

STETLER, C. B.; MORSI, D.; RUCKI, S.; BROUGHTON, S.; CORRIGAN, B. et al. Utilization-focused integrative reviews in a nursing service. Applied Nursing Research, v. 11, n. 4, p. 195-206, 1998. Disponível em: <https://www.sciencedirect.com/science/article/pii/S0897189798803297>. DOI: https://doi.org/10.1016/S0897-1897(98)80329-7.

TEIGA, A. J. Gestão de pessoas. 1. ed. Curitiba, PR: IESDE Brasil, 2012.

TREVELATO, E.; SILVA, G.; PANTALEÃO, J.; FONSECA, B. G. A obtenção de vantagem competitiva através do treinamento e desenvolvimento de pessoas. Revista Científica, v. 1, n. 1, 2018. Disponível em: <http://revistas.unilago.edu.br/index.php/revista-cientifica/article/view/84>.

URSI, E. S. Prevenção de lesões de pele no perioperatório: revisão integrativa da literatura. Dissertação (Mestrado em Enfermagem) - Escola de Enfermagem, Universidade de São Paulo, Ribeirão Preto, 2005. Disponível em: <https://teses.usp.br/teses/disponiveis/22/22132/tde-18072005-095456/pt-br.php>.

DOI: 10.11606/D.22.2005.tde-18072005-095456. 
VESTENA, D.; SILVA, E. T. da; TRAVERSO, L. D.; FRIZZO, K.; DAMKE, L. I. et al. A influência do treinamento e desenvolvimento no desempenho de uma empresa de varejo: um estudo na Eny Calçados Ltda. Revista Visão: Gestão Organizacional, v. 7 n. 1, p. 120-136, 2018. Disponível em: $<$ https://periodicos.uniarp.edu.br/index.php/visao/article/view/1399>. DOI: https://doi.org/10.33362/visao.v7i1.1399. 